\title{
Tutorial
}

\section{Writing Your First Scholarly Article: A Guide for Budding Authors in Librarianship}

\section{Scott Nicholson}

This series of questions and answers is designed to help you take the first steps toward the successful production of a scholarly article in librarianship. You may find yourself in a library position that requires writing or you may have just decided that you are ready to share your findings, experiences, and knowledge with the current and future generations of librarians. While following the guidelines listed here will not guarantee that you will be successful, these steps will take you closer to discovering the thrill of seeing your name in print and making a difference in the field.

\section{What should I write about?}

Perhaps you already have an idea based upon your experiences and expertise, or perhaps you aren't sure which of those ideas you should write about. The best way to start writing is to read other articles! Many scholarly articles end with a Future Research section that outlines other projects and questions that the article suggests. It is useful to contact the author of a piece that holds a Future Research seed to ensure that the author has not already taken on that challenge. Sometimes, the original author may be interested in collaborating with you to explore that next question.

Scott Nicholson (srnichol@syr.edu) is an Assistant Professor in the School of Information Studies, Syracuse University, New York.

\section{How do I start?}

Scholarship is an iterative process, in that works that you produce are bricks in an ever-rising wall. Your brick will build upon the works of others and, once published, others will build upon your work. Because of this, it is essential to begin with a review of related literature. Search in bibliographic and citation databases as well as Web search tools to see if others have done similar projects to your own. The advantage of finding related literature is that you can learn from the mistakes of others and avoid duplicating works (unless your plan is to replicate the work of others).

Starting with the work of others allows you to place your brick on the wall. If you do not explicitly discuss how your scholarship relates to the scholarship of others, only those having familiarity with the literature will be able to understand how your work fits in with that of previous authors. In addition, it's easier to build upon your work if those who read it have a better idea of the scholarly landscape in which your work lives.

As you go out and discover literature, it is crucial to keep citation information about each item. Much of what you will cite will be book chapters or articles in journals, and you will save yourself time and trouble later if you make a printed copy of source items and record bibliographic information on that copy. Recording the title of the work, the full names (including middle initials) of authors and editors, page range, volume, issue, date, publisher and place of publication, URL and date accessed, and any other bibliographic information at the time of collection will save you headaches later when you have to create your references list. As different journals have different citation requirements, having all of this information allows you the flexibility of adapting to different styles.

One type of scholarship produced by libraries is the "how our library did something well" article. While a case study of your library can be an appropriate area of discussion, it is critical to position these pieces within the scholarship of the field. This allows readers to better understand how applicable your findings are to their own libraries. The concept illustrates the difference between the practice of librarianship and library science. Library science is the study of librarianship and includes the generalization of library practice in one setting to other settings.

Before starting your writing, talk about your idea with your colleagues, which will help you refine your ideas. It will also generate some excitement and publicity about your work, which can help inspire you to continue in the writing process. Colleagues can help you consider different places where similar works may already exist and might even open your eyes to similar work in another discipline. You may find a colleague who wants to coauthor the piece with you, which can make the project easier to complete and richer through the collaborative process.

Another important early step is to consider the journals you would like to be published in. Many times, it can be fruitful to publish in the journal that has published works that are in your literature review. Considering the journal at this point will allow you to correctly focus the scope, length, and style of your article to the requirements of your desired journal. Your article should match the length and tone of other articles in that journal. Most journals provide instructions to authors in each issue or on the Web; the information page for ITAL authors is at www.ala.org/ala/ lita/litapublications/ital/information authors.htm.

\section{How can I find funding for my research?}

Some projects can't be easily done in your spare time and require resources for surveys, statistical analysis, travel, or other research costs. You will find that successful requests for funding 
start with a literature review and a research plan. Developing these before requesting funding will make your request for funding much stronger, as you will be able to demonstrate how your work will sit within a larger context of scholarship.

You will need to develop a budget for your funding request. This budget will come together more easily if you have planned out your research. It may be useful or even required for you to develop a set of outcomes for your project and how you will be assessing those outcomes (find more information on outcome-based evaluation through the IMLS Web site at www.imls.gov/grants/current/ crnt_obe.htm). Developing this plan will give you a more concrete idea of what resources you will need and when, as well as how you can use the results of your work.

Resources for research may come from the inside, such as the library or the parent organization of the library, or from an external source, such as a granting body or a corporate donor. In choosing an organization for selection, you should consider who would most benefit from the research, as the request for funding should focus on the benefit to the granting body. Many libraries and schools do have small pots of money available for research that will benefit that institution and that, many times, go untapped due to a lack of interest. Granting organizations put out formal calls for grant proposals. These can result in a grant that would carry some prestige but would require a detailed formal application that can take months of writing and waiting. Another approach is to work with a corporate or nonprofit organization that gives grants. If your organization has a development office, this office may be able to help connect you with a potential supporter of your work.

\section{How do I actually do the research?}

Just as the most critical part of a dissertation is the proposal, a good research plan will make your research process run smoothly. Before you start the research, write the literature review and the research plan as part of an article. It can be useful to create tables and charts with dummy data that will show how you plan to present results. Doing this allows you to notice gaps in your data-collection plan well before you start that process. In many research projects, you only have a single chance to collect data; therefore, it's important to plan out the process before you begin.

\section{How do I start writing the paper?}

The best way to start the writing process is to just write. Don't worry about coming up with a title; the title will develop as the work develops. You can skip over the abstract and introduction; these can be much easier to write after the main body of the article is complete. If you've followed the advice in this paper, then you've already written a literature review and perhaps a research plan; these make a good starting point for your article.

One way to develop the body of the article is to develop an outline of headings and subheadings. Starting with this type of outline forces you to think through your entire article and can help you identify holes in your preparation. Once you have the outline completed, you can then fill in the outline by adding text to the headings and subheadings. This approach will keep your thinking organized in a way typically used in scholarly writing.

Scholarly writing is different than creative writing. Many librarians with a humanities background face some challenges in transitioning to a different writing style. Scholarly writing is terse; Strunk and White's The Elements of Style (2000) focuses on succinct writing and can help you refresh your writing skills. ${ }^{1}$
If you are having difficulty finding the time to write, it can be useful to set a small quota of writing that you will do every day. A quota such as four paragraphs a day is a reasonable amount to fit into even a busy day, but it will result in the completion of your first draft in only a few weeks.

\section{I'm finished with my first complete draft! Now what?}

While you will be excited with the completion of the draft, it's not appropriate to send that off to a journal just yet. Take a few days off and let your mind settle from the writing, then go back and reread your article carefully. Examine each sentence for a subject and a verb, and remove unneeded words, phrases, sentences, paragraphs, or even pages. Try to tighten and clean your writing by replacing figures of speech with statements that actually say what you mean in that situation and removing unneeded references to first- and second-person pronouns. Working through the entire article in this way greatly improves your writing and reduces the review and editing time needed for the article.

After this, have several colleagues read your work. Some of these might be people with whom you shared your original ideas, and others may be new to the concepts. It can be useful to have members of different departments and with different backgrounds read the piece. Ask them if they can read your work by a specific date, as this type of review work is easy to put off when work gets busy. These colleagues may be people who work in your institution or may be people you have met online. If you know nobody who would be appropriate, consider putting out a request for assistance on a library discussion list focused on your research topic.

Dealing with the comments from others requires you to set aside your 
defenses. You did spend a lot of time on this work and it can be easy to slip into a defensive mode. Attempt to read their comments from an objective viewpoint. Remember-these people are spending their time to help you, and a comment you disagree with at first blush may make more sense if you consider the question "Why would someone say this about my work?" Putting yourself into the reader's shoes can aid you in the creation of a piece that speaks to many audiences.

\section{What goes on when I submit my work?}

At this point, your readers have looked at the piece, and you have made corrections on it. Now you're ready to submit your work. Follow the directions of the target journal, including length, citation format, and method of submission. If submission is made by e-mail, it would be appropriate to send a follow-up e-mail a few days after submission to ensure the work was received; it can be very frustrating to realize, after a month of waiting, that the editor never got the work.

Once you have submitted your work, the editor will briefly review it to ensure it is an appropriate submission for the journal. If it is appropriate, then the editor will pass the article on to one or more reviewers; if not, you will receive a note fairly quickly letting you know that you should pick another journal. If the reviewing process is "blind," then you will not know who your reviewers are, but they may know your identity. If the process is "double-blind," neither reviewer nor author will know the identity of the other. The reviewers will read the article and then submit comments and a recommendation to the editor. The editor will collect comments from all of the reviewers and put them together, and send those comments to you. This will always take longer than you would prefer; in reality, it will usually take two to six months, depending upon the journal.

After a few months, it would be appropriate for you to contact the editor and ask about the progress on the article and when you should expect comments. Do not expect to have your article accepted on the first pass. The common responses are:

- Reject. At this point, you can read the comments provided, make changes, and submit it to another journal.

- Revise and resubmit. The journal is not making a commitment to you, but they are willing to take another look if you are willing to make changes. This is a common response for first submissions.

- Accept with major changes. The journal is interested in publishing the article, but it will require reworking.

- Accept with minor changes. You will be presented with a series of small changes. Some of these might be required and others might be your choice.

- Accept. The article is through the reviewing process and is on to the next stage.

This is an iterative process. You will most likely go through several cycles of this before your article is accepted, and staying dedicated to the process is key to its success. It can be disheartening to have made three rounds of changes only to face another round of small changes. Ideally, each set of requested changes should be smaller (and take less time) until you reach the acceptance level.

Do not submit your work to multiple journals at the same time. If you choose to withdraw your work from one journal and submit it to another, let the editor know that you are doing this (assuming they have not rejected your work).

\section{My article has been accepted. When will it come out?}

Once your article is accepted, it will be sent into a copyediting process. The copy editor will contact you with more questions that focus more on writing and citation flaws than on content. After making more corrections, you will receive a proof to review (usually with a very tight deadline). This proof will be what comes out in the journal, so check important things like your name, institutions, and contact information carefully. The journal will usually come out several months after you see this final proof. The process from acceptance to publication can take from six months to two years (or more), depending on how much of a publication queue the journal has. The editor should be able to give you an estimate as to when the article will come out after full acceptance.

\section{Can I put a copy of my article online?}

It depends upon the copyright agreement that you sign. Many publishers will allow you to put a copy of your article on a local or institutional Web site with an appropriate citation. Some allow you to put up a preprint, which would be the version after copyediting but not the final proof version. If the copyright agreement doesn't say anything about this, then ask the editor of the journal about the policy of authors mounting their own articles on a Web site.

\section{Conclusion}

Writing an article and getting it published is akin to having a child. Your child will have a life of its own, and others may notice this new piece of knowledge and build upon it to improve their own library services 
or even make their own works. It is a way to make a difference that goes far beyond the walls of your own library, to extend your professional network, and to engage other scholars in the continued development of the knowledge base of our field.

\section{Reference}

1. W. Strunk Jr. and E. B. White, The Elements of Style (Boston: Allyn \& Bacon, 2000).

\section{For More Information:}

W. Crawford, First Have Something to Say: Writing for the Library Profession (Chicago: ALA, 2003).

R. Gordon, The Librarian's Guide to Writing for Publication (Lanham, Md.: Scarecrow, 2004).

L. Hinchliffe and J. Dorner, eds., How to Get Published in LIS Journals: A Practical Guide (San Diego: Elsevier, 2003), www .elsevier.com/framework_librarians/Lib raryConnect/lcpamphlet2.pdf, (accessed Feb. 8, 2006). 